\title{
Impact of Perceived Value on Customer Satisfaction and Continuance Intention of Bicycle Sharing Service
}

\author{
Zhen Shao \\ Harbin Institute of Technology \\ shaozhen@hit.edu.cn
}

\author{
Yanning Guo \\ Harbin Institute of Technology \\ guoyn@hit.edu.cn
}

\author{
Chaoyi Ge \\ Harbin Institute of Technology \\ 317130735@qq.com
}

\begin{abstract}
Bicycle sharing service has been identified as one of the most significant applications in the sharing economy, yet few studies have explored its value stream from a customer perception perspective. Drawing upon value creation theoretical framework, this study proposes a research model to examine the impact mechanism of four value streams on customer satisfaction and continuance intention of bicycle sharing service. An empirical study was conducted and 293 valid data was collected from users of two leading bicycle-sharing platforms in China. Structural equation modeling technique was used to examine the research model. The empirical results suggest that emotional value is the most significant antecedent of customer satisfaction and continuance intention, followed by functional value and economic value. While environmental value has a positive but weaker influence on customer satisfaction. A post-hoc analysis further suggests that gender difference exists on the association between the four value streams and customer satisfaction.
\end{abstract}

\section{Introduction}

With the digital technology advance and innovation in the past few years, sharing economy has emerged as a new scheme of business model, which is transforming the society by connecting online platforms with offline activities [1]. Compared with traditional economies, the sharing economy builds on peer-to-peer based activities of obtaining, giving, or sharing the access to goods and services, coordinated through online platforms [2, 3]. People prefer to assess and use the physical or intellectual resources instead of obtaining their ownership in the emerging trend of sharing economy $[3,4]$. According to a recent market investigation, $44 \%$ of respondents reported that they are familiar with the sharing economy and have gained benefits from the service [5].

In China, sharing economy has been widely applied in various industries of accommodation, transportation and dining. In particular, bicycle-sharing application has gained rapid development in the past few years. Numerous online sharing platforms have emerged and popularized to facilitate transactions more efficiently and effectively. In particular, "OFO" and "Mobike" are recognized as two most leading bicycle sharing platforms in the Chinese marketplace [6]. People prefer to select bicycle sharing for travelling in a short distance since it is more convenient and economic, and is beneficial for the environmental sustainability compared with other travelling schemes. According to a statistical analysis of iResearch, the market size of bicycle-sharing service has achieved 3.857 billion RMB up to the second quarter of 2017 in China, and it will keep growing in the next few years [6].

Given the rapid development of bicycle-sharing in practical applications, academic studies have been conducted to examine the significant antecedents that promote individuals' continuance intention of bicycle sharing service from different theoretical perspectives. For example, [7] investigated the critical motivations that drive commuters' ridesharing intention in Jakarta based on a pro-environmental behavior framework. The empirical results suggested that attitude, perceived behavior control and personal norm are significant drivers of users' behavioral intention. In another study, [8] examined the cognitive factors that promote user participation in the context of bicycle sharing. It was found that self-efficacy, cognitive of duty, anticipation of rewards and identification are positively associated with user co-creation behaviors. In a recent study, [9] examined the effect of perceived service quality on customers' behaviors intention towards bicycle sharing service. The empirical results indicated that perceived tangible, response, empathy and reliability are significant service qualities that positively influence customer satisfaction and continuance intention.

Despite previous studies have provided us a theoretical framework to understand customers' behaviors in the context of bicycle sharing, to the best of our knowledge, few studies have empirically examined customers' continuance intention from a value creation theoretical perspective. In the service 
marketing, value refers to customers' overall evaluation of the usefulness of a product or service based on perception of what is obtained and what is provided [10, 11]. Since the premise of sharing economy is to unleash the value from underutilized personal commodities [12, 13], it is necessary to conduct a systematic and comprehensive analysis of different value steams, in order to provide a comprehensive understanding of value creation in the context of bicycle sharing from a customer perception perspective.

The remaining open question drives the research objective of this study. Drawing upon value creation framework, this study aims to examine the influences of four value streams, regarding functional value, emotional value, economic value and environmental value, on user satisfaction and continuance intention of bicycle sharing service. The following research question is proposed to address the aforementioned research objective: How do different types of value streams influence customer satisfaction and continuance intention in the context of bicycle sharing?

The reminder of the paper is organized as follows. The next section reviews the previous literature in value creation as a theoretical foundation. The third section proposes the research model and articulate the theoretical logic of each research hypotheses. The fourth section illustrates the research methodology in terms of instrument design, data collection procedure and structural equation modelling analysis. The final section concludes with a discussion of the research findings, theoretical and practical implications and future research directions.

\section{Theoretical Foundation}

\subsection{Customer Value Creation}

The concept of customer value was firstly proposed in marketing research, which was defined as "consumer's overall assessment of the utility of a product (or service) based on perception of what is received and what is given" [14]. Drawing upon a value creation perspective, firms must understand and satisfy customers' values in order to achieve competitive advantage in the marketplace $[15,16]$. In the past decade, customer value has been divided into various typologies to evaluate the perceived utility of a product or service from different perspectives. For example, [16] divided customer value into four categories, regarding functional value, emotional value, economic value (price value), and social value. Specifically, functional value refers to customers' perceived practical or technical benefits gained by using a product or service, which captures the utility resulting from the actual performance [16, 17]. Emotional value represents customers' affective state obtained through the experience of a product or service, which usually derives from pleasant experiences and feelings $[18,17]$. Economic value describes customers' cognitive tradeoff between perceived benefits of a service and the monetary costs for using them $[19,16]$. While social value refers to the utility derived from a product or service to enhance a user's social image in accordance with other people's expectations [16, 17]. The four dimensions of customer value have been widely applied in mobile commerce and social commerce research. It was argued that the significance of different value typologies depends on the type of product or service being used [16].

In the context of bicycle sharing, the widespread application of digital technologies has changed the business model from business-to-customer (B2C) to customer-to-business (C2B), and customers' perceived value play a more significant role in facilitating customer satisfaction and continuance intention. On the one hand, the new business model of bicycle sharing can provide customers with a more efficient, enjoyable and cost-saving travelling method, which largely manifests customers' perceived functional, emotional and economic values, as suggested in [16]'s framework. On the other hand, bicycle sharing service can also provide benefits to the customers by reducing environmental pollution and transforming societies towards sustainable development, which manifests the environmental value perceived by customers. Thus this study includes functional value, emotional value, economic value and environmental value in the framework, in order to better adapt to the research context of bicycle sharing. Previous literature indicates that social value lies in satisfying customers' needs to have real social interaction in cyberspace [43]. Since bicycle sharing application does not include a social interaction functionality, we do not include social value in the framework.

The definitions and corresponding references of customer values are provided in Table 1.

Table 1. Definitions of Customer Values

\begin{tabular}{l|l|l}
\hline $\begin{array}{l}\text { Customer } \\
\text { Values }\end{array}$ & Definitions & $\begin{array}{l}\text { Reference } \\
\text { s }\end{array}$ \\
\hline $\begin{array}{l}\text { Functional } \\
\text { Value }\end{array}$ & $\begin{array}{l}\text { The utility derived from using a } \\
\text { product or service due to the } \\
\text { technical or practical benefits. }\end{array}$ & {$[16,17]$} \\
\hline $\begin{array}{l}\text { Emotional } \\
\text { value }\end{array}$ & $\begin{array}{l}\text { Theelings or affective states that a } \\
\text { product or service generates, such } \\
\text { as enjoyment and elevated moods } \\
\text { perceived by the user. }\end{array}$ & {$[16,17]$} \\
\hline
\end{tabular}




\begin{tabular}{l|l|l}
\hline Economic & $\begin{array}{l}\text { The utility derived from using a } \\
\text { product or service due to the } \\
\text { reduction of its perceived costs. }\end{array}$ & {$[16,17]$} \\
\hline $\begin{array}{l}\text { Environme } \\
\text { ntal value }\end{array}$ & $\begin{array}{l}\text { The utility derived from using a } \\
\text { product or service due to the } \\
\text { reduction of environmental } \\
\text { pollution. }\end{array}$ & {$[3]$} \\
\hline
\end{tabular}

\section{Research Model and Hypotheses}

Drawing upon customer value creation framework, this study develops a research model to examine the specific influences of four value streams, specifically functional value, emotional value, economic value and environmental value, on customer satisfaction and continuance intention in the context of bicycle sharing. In particular, this study adds age, educational background and use frequency as control variables in the research model, as suggested in the previous literature. Figure 1 illustrates the research model and corresponding hypotheses.

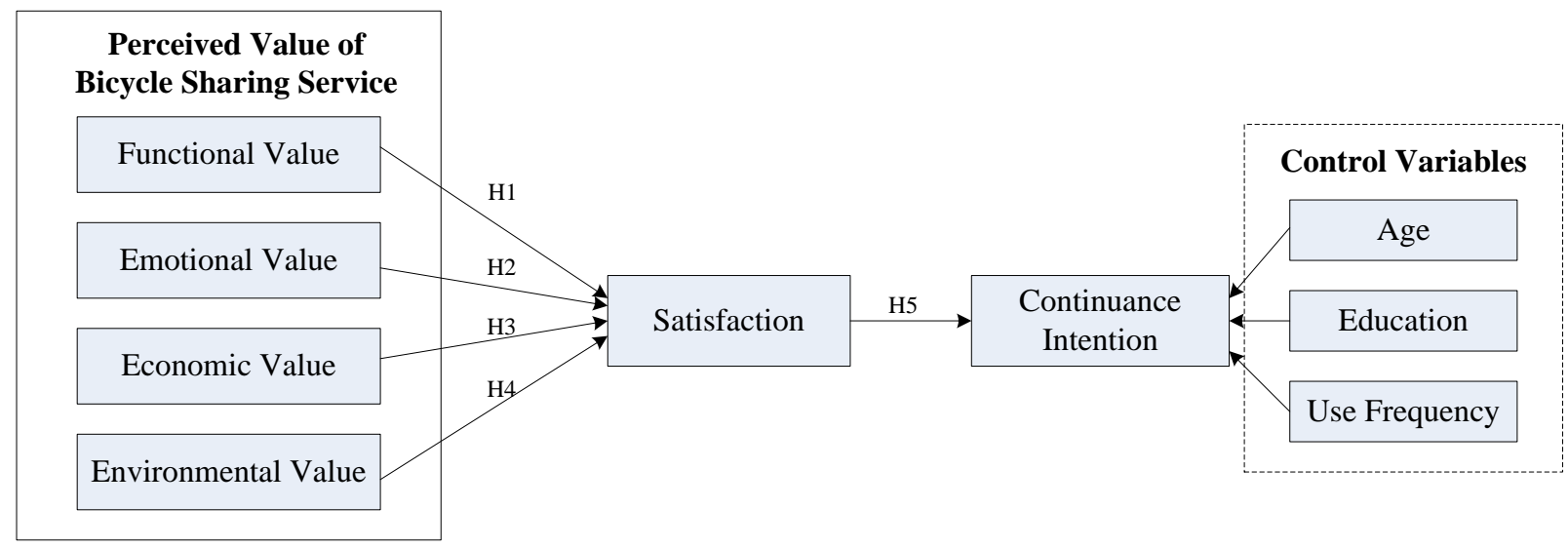

Figure 1. Research model

\subsection{Influence of Functional Value on User Satisfaction}

According to the value creation framework, individuals' feelings are significantly affected by the utility obtained from a product (or service) [16]. If a customer perceives a higher functional value of a product or service (i.e. an acceptable standard of quality or a high practical utility) to satisfy his/her requirements and needs, the overall evaluation and feeling derived from the product or service would be enhanced accordingly [16]. The impact of functional value on customer's cognitive reaction and behavioral intention has been examined in the previous literature. For example, [28] found that utilitarian benefit is positively associated with user satisfaction in the social virtual world continuance. In another study, [11] reported that functional value is positively related with user-system interaction, which in turn promotes user performance in the digital content usage.

In the context of bicycle sharing, functional value refers to customers' perception of using the service for fulfilling instrumental requirements and achieving purposive tasks. If the sharing platform can provide customers with an effective travelling option and help them arrive in the destination conveniently and rapidly using GPS and big data technologies, customers' perception of functional value will be enhanced accordingly. This is beneficial to generate a positive evaluation towards the bicycle sharing service, which in turn enhances customer satisfaction. In this regard, we propose that:

H1. Perceived functional value of bicycle sharing service is positively associated with customer satisfaction.

\subsection{Influence of Emotional Value on User Satisfaction}

Drawing upon the theoretical framework of value creation, emotional value plays an important role in facilitating customer satisfaction [16]. When a customer is emotionally satisfied, he or she is more likely to generate a higher degree of overall evaluation of the product or service [27, 16]. Previous literature also provided empirical evidence for the positive relationship between emotional benefit and user satisfaction. For example, [29] found that emotional value is the most significant factor that positively affects customer satisfaction and loyalty. In another study, [30] reported that a higher emotional value would increase the degree of customer satisfaction in 
the e-commerce marketplace.

In the context of bicycle sharing, emotional value refers to the level of pleasure and enjoyment perceived by customers when using the bicycle sharing service for daily travelling. An investigation in China reported that a large amount of users prefer bicycle sharing to other optional vehicles because they enjoyed the new style of daily travelling [6]. The joyful experience of bicycle sharing service will make customers feel emotionally agreeable. Accordingly, it is reasonable to believe that customers' positive feelings generated from using the bicycle sharing service is beneficial to enhance their satisfaction. Thus we propose the following hypothesis:

H2. Perceived emotional value of bicycle sharing service is positively associated with customer satisfaction.

\subsection{Influence of Economic Value on User Satisfaction}

In marketing research, monetary cost (price) is usually associated with the quality of a product or service to determine its value [14]. In the context of technology use, price was also recognized as a significant factor for decision making since customers have to bear the cost associated with the purchase of a product or service [31]. For example, the popularity of Alipay in China results from its earlier free of charge and low pricing strategy. Previous literature also provided empirical evidence for the positive relationship between economic benefit and user satisfaction. For instance, [28] reported that perceived cost has the greatest effect on customer satisfaction when a customer makes a purchase decision of $3 \mathrm{G}$ service in China. In a recent study, [24] found that perceived monetary value is positively associated with user satisfaction and behavioral intention for paid mobile apps.

In the context of bicycle sharing, economic value represents customers' cognitive tradeoff between perceived benefit of the bicycle sharing service and the monetary cost for using it. Compared with purchasing, sharing a product or service is generally regarded as economical [3]. According to an investigation by [6], price was considered as a significant factor when customers decide whether to use the bicycle sharing service. If the benefit of using the service is greater than the monetary cost, customers will be satisfied and more likely to continue using the service for daily travelling. The above analysis leads to the following hypothesis:

H3. Perceived economic value of bicycle sharing service is positively associated with customer satisfaction

\subsection{Influence of Environmental Value on User Satisfaction}

Participation in sharing a product or service is generally expected to be highly ecologically sustainable, and customers prefer to create more value for the ecological environment through using a green product or service [17]. Previous studies have provided empirical evidence for the positive relationship between environmental benefit and user cognitive reaction as well as behavioral intention. Specifically, [3] indicated that perceived sustainability has a strong influence on customer's attitude towards the collaborative consumption in the sharing economy. In another study, [32] found that perceived value of green consumption is significantly associated with customer's repurchase intention of a product or service.

In the context of bicycle sharing, environmental value refers to customers' perceived utility of the bicycle sharing service in reducing environmental pollution and promoting sustainability. Compared with other travelling modes, bicycle sharing plays a more significant role in environmental protection through reduction of carbon emissions. This is beneficial to foster a sustainable marketplace and satisfy the environmental benefits of collaborative consumption for future generations [33, 34]. If customers perceive higher environmental benefits of using the bicycle sharing for daily travelling, their affective reactions towards the service will be enhanced accordingly. Based on the above arguments, we propose that:

H4. Perceived environmental value of bicycle sharing service is positively associated with customer satisfaction.

\subsection{Influence of User Satisfaction on Continuance Intention}

Satisfaction refers to an individual's positive affective reaction resulting from his/her appraisal of surrounding circumstances [26]. Previous literature suggests that customers' continuance intention primarily depends on the degree of satisfaction with previous transaction experiences [22, 23]. Satisfactory experiences are beneficial to promote customers' continuance intention of a product or service, while dissatisfactory reactions may impede individuals from reusing the product or service [26]. Previous literature has examined the relationship between customer satisfaction and continuance intention in various research contexts. For example, [35] reported that customer satisfaction is positively associated with their 
stickiness of group-buying. In another study, [36] indicated that customer satisfaction is one of the most significant antecedents of repurchase intention.

In the context of bicycle sharing, satisfaction represents customers' affective reactions resulting from an appraisal of the bicycle sharing service. When customers have generated higher positive affective reactions based on previous usage experiences, they are more likely to reuse the bicycle sharing service for daily travelling. Thus we infer that customers' degree of satisfaction would have a significant influence on their intention to continue using the bicycle sharing service, and propose the following hypothesis:

H5. Customer satisfaction is positively associated with continuance intention.

\section{Research Methodology}

\subsection{Instrument Design}

The instrument was designed based on the previous literature. Each construct was measured using seven-point Likert scale, ranging from "strongly disagree" (1) to "strongly agree" (7). Specifically, items for functional value, emotional value and economic value were operationalized based on [16]'s study. Environmental value is a newly developed construct, and its measurement items were adapted from the construct of "sustainability" in [3]'s study. Example items for "environmental value" is described as follows: "The bicycle sharing service is beneficial to reduce environment pollution" and "The bicycle sharing service is a sustainable mode of consumption". Satisfaction and continuance intention were designed drawing upon [22]'s study. The instrument was refined to better fit the research context of bicycle sharing service. A pilot study was conducted before the final data collection. A total of 96 college students with bicycle sharing usage experiences were invited to complete the questionnaires, and 92 valid questionnaires were received. We deleted items with factor loadings lower than 0.7 to improve the reliability and validity of the constructs [37]. Table 2 describes the items for each construct and corresponding references.

Table 2. Constructs and items

\begin{tabular}{|c|c|c|}
\hline Constructs & Items & References \\
\hline Functional Value & FU1- FU3 & \multirow{3}{*}{ [16] } \\
\hline Emotional Value & EM1-EM3 & \\
\hline Economic Value & EC1-EC3 & \\
\hline Environmental Value & EN1-EN3 & [3] \\
\hline Satisfaction & SA1-SA3 & \multirow[b]{2}{*}[22]{} \\
\hline $\begin{array}{l}\text { Continuance } \\
\text { Intention }\end{array}$ & CI1-CI3 & \\
\hline
\end{tabular}

\subsection{Data Collection}

The final data collection was conducted using online survey during September to November in the year of 2017. In particular, individuals who have usage experiences of OFO or Mobike bicycle sharing service were selected as respondents, since these two platforms occupy more than $80 \%$ markets of bicycle sharing. Thus we believe that the two leading platforms are representative of the bicycle sharing marketplace in China. We first invited several individuals who have usage experiences of OFO or Mobike to complete the questionnaires using mobile phones. Then we asked the respondents to share the survey in the "WeChat Moments" and invite their friends who have used bicycle sharing service to complete the questionnaires. A reward of $5 \mathrm{RMB}$ was provided to the respondents who participated in the investigations. Totally 316 questionnaires were collected from individuals of 15 cities in China. We deleted the questionnaires with no usage experience of OFO or Mobike, and the questionnaires with missing data or inaccurate data (all answers of 7 or 1), and finally got 293 valid questionnaires for data analysis. The sample characteristics of the investigation is illustrated in Table 3.

As illustrated in Table 3, there is an average distribution of male and female users. Most of the respondents age between 18 and 30, and most of them possess a bachelor degree or above. With regard to use frequency, most of the respondents use bicycle sharing within 3 hours per week to satisfy "the last kilometer" short distance requirement. Overall, the demographics of the respondents are basically consistent with the investigation in China [6], suggesting that our sample is representative of the actual users of bicycle sharing service in China.

Table 3. Sample characteristics

\begin{tabular}{l|l|l|l}
\hline Items & Types & Numbers & Percentage \\
\hline \multirow{3}{*}{ Gender } & Males & 149 & $50.85 \%$ \\
\cline { 2 - 4 } & Females & 144 & $49.15 \%$ \\
\hline \multirow{4}{*}{ Age } & Below 18 & 8 & $2.73 \%$ \\
\cline { 2 - 4 } & $18-30$ & 236 & $80.55 \%$ \\
\cline { 2 - 4 } & Above 30 & 49 & $16.72 \%$ \\
\hline \multirow{4}{*}{ Education } & $\begin{array}{l}\text { Senior high } \\
\text { school and below }\end{array}$ & 43 & $14.68 \%$ \\
\cline { 2 - 4 } & Bachelor & 172 & $58.70 \%$ \\
\cline { 2 - 4 } Use & Master and above & 78 & $26.62 \%$ \\
\hline \multirow{4}{*}{ Frequency } & $\begin{array}{l}\text { Less than 3 hours } \\
\text { per week }\end{array}$ & 221 & $75.43 \%$ \\
\cline { 2 - 4 } & $\begin{array}{l}\text { 3-5 hours per } \\
\text { week }\end{array}$ & 46 & $15.70 \%$ \\
\cline { 2 - 4 } & $\begin{array}{l}\text { More than 5 hours } \\
\text { per week }\end{array}$ & 26 & $8.87 \%$ \\
\hline
\end{tabular}




\subsection{Structural Equation Model Analysis}

Structural equation modelling (SEM) method was used to examine the research model since it allows the incorporation and process of both unobserved (latent) and observed variables simultaneously, and can handle errors of measurement within exogenous variables in a better manner [38]. In particular, we selected SmartPLS as a primary statistical tool for data analysis since it is more suited for theory exploration and prediction compared with covariance-based SEM methods [38]. The sample size of 293 can satisfy the requirements of PLS-either 10 times the larger measurement number within the same construct or 10 times the larger construct number affecting the same construct [37].

\subsubsection{Measurement Model Analysis.}

The measurement model was examined to analyze the reliability and convergent validity of the constructs. As noted in Table 4, the item loadings of all the constructs have exceeded 0.8 , and the Cronbach's alpha for each construct is highly above 0.7 . In addition, the average variance extracted (AVE) for each construct is higher than 0.8 . The above results demonstrate a good reliability and convergent validity of the measurement model [37].

Table 4. Construct reliability and validity analysis

\begin{tabular}{|c|c|c|c|c|}
\hline Construct & Items & Factor Loadings & Cronbach's alpha & AVE \\
\hline \multirow{3}{*}{$\begin{array}{l}\text { Functional Value } \\
\text { (FU) }\end{array}$} & FU1 & 0.949 & \multirow{3}{*}{0.940} & \multirow{3}{*}{0.893} \\
\hline & FU2 & 0.959 & & \\
\hline & FU3 & 0.927 & & \\
\hline \multirow{3}{*}{$\begin{array}{l}\text { Emotional Value } \\
\text { (EM) }\end{array}$} & EM1 & 0.948 & \multirow{3}{*}{0.943} & \multirow{3}{*}{0.899} \\
\hline & EM2 & 0.964 & & \\
\hline & EM3 & 0.933 & & \\
\hline \multirow{3}{*}{$\begin{array}{l}\text { Economic Value } \\
\text { (EC) }\end{array}$} & $\mathrm{EC} 1$ & 0.939 & \multirow{3}{*}{0.932} & \multirow{3}{*}{0.880} \\
\hline & $\mathrm{EC} 2$ & 0.934 & & \\
\hline & EC3 & 0.941 & & \\
\hline \multirow{3}{*}{$\begin{array}{l}\text { Environmental Value } \\
\text { (EN) }\end{array}$} & EN1 & 0.960 & \multirow{3}{*}{0.952} & \multirow{3}{*}{0.912} \\
\hline & EN2 & 0.947 & & \\
\hline & EN3 & 0.957 & & \\
\hline \multirow{3}{*}{$\begin{array}{l}\text { Satisfaction } \\
\text { (SA) }\end{array}$} & SA1 & 0.955 & \multirow{3}{*}{0.947} & \multirow{3}{*}{0.905} \\
\hline & SA2 & 0.956 & & \\
\hline & SA3 & 0.943 & & \\
\hline \multirow{3}{*}{$\begin{array}{l}\text { Continuance Intention } \\
\text { (CI) }\end{array}$} & CI1 & 0.918 & \multirow{3}{*}{0.955} & \multirow{3}{*}{0.918} \\
\hline & $\mathrm{CI} 2$ & 0.916 & & \\
\hline & $\mathrm{CI} 3$ & 0.910 & & \\
\hline
\end{tabular}

Table 5. Correlation analysis between constructs

\begin{tabular}{l|l|l|l|l|l|l}
\hline & $\begin{array}{l}\text { Functional } \\
\text { Value }\end{array}$ & $\begin{array}{l}\text { Emotional } \\
\text { Value }\end{array}$ & $\begin{array}{l}\text { Economic } \\
\text { Value }\end{array}$ & $\begin{array}{l}\text { Environmental } \\
\text { Value }\end{array}$ & Satisfaction & $\begin{array}{l}\text { Continuance } \\
\text { Intention }\end{array}$ \\
\hline FU & 0.945 & & & & & \\
\hline EM & 0.798 & 0.948 & & & & \\
\hline EC & 0.551 & 0.687 & 0.938 & & & \\
\hline EN & 0.678 & 0.691 & 0.486 & 0.955 & & \\
\hline SA & 0.791 & 0.795 & 0.644 & 0.636 & 0.951 & \\
\hline CI & 0.699 & 0.773 & 0.551 & 0.729 & 0.692 & 0.958 \\
\hline
\end{tabular}

(Note: Values on the diagonal are square root of AVEs) 
Following [37]'s procedure, discriminant validity is examined by evaluating if the square root of the AVE for each construct exceeds that construct's correlation with other constructs. This study conducted a correlation analysis between the constructs. As described in Table 5, the square root of the AVE for each construct (the values on the diagonal) is much higher than that construct's correlation with other constructs, providing an adequate support for the discriminant validity of the measurement model [37].

\subsubsection{Structural Model Analysis.}

The structural model was then analyzed to examine the hypotheses and explanatory power of the research model. Bootstrapping procedure method was employed to calculate the statistical significance of the parameter estimates in order to derive valid standard errors or t-values [39]. The analysis result is described in Figure 2.

As noted in Figure 2, functional value is positively associated with satisfaction $(\beta=0.353, p<0.01)$, thus supports hypothesis $\mathrm{H} 1$. The result suggests that customers' satisfaction will be enhanced significantly if they perceive a high value of the bicycle sharing service to satisfy their travelling requirements. As hypothesized in $\mathrm{H} 2$, emotional value has a strong influence on satisfaction $(\beta=0.391, p<0.01)$. The result demonstrates that customers' satisfaction towards the bicycle-sharing service will be increased greatly when the hedonic and affective values are achieved. As illustrated in Figure 2, economic value is positively associated with satisfaction $(\beta=0.118, p<0.01)$, thus supports hypothesis $\mathrm{H} 3$. The result indicates that customers will be more satisfied if they perceive a higher economic value of the bicycle sharing service due to the reduction of monetary cost compared with other travelling options. As noted in Figure 2, environmental value is positively related with satisfaction $(\beta=0.078, p<0.05)$. The result provides support for hypothesis $\mathrm{H} 4$, demonstrating that customers are more satisfied of the bicycle sharing service if they perceive a higher value of environmental protection and ecological sustainability. However, compared with other value streams, environmental value may not play a dominant role in determining customers' cognitive reactions and behavioral intentions since it has a weaker influence on customer satisfaction and continuance intention. Consistent with the previous research findings [22], satisfaction has a strong influence on continuance intention $(\beta=0.636$, $\mathrm{p}<0.01$ ), thus supports hypothesis H5. The result indicates that customers' continuance intention of bicycle sharing service is largely determined by their satisfaction resulted from previous usage experiences.

Regarding the influence of control variables, we note from Figure 2 that use frequency has a significant influence on continuance intention, while age and education background are not significantly associated with continuance intention. With regard to the explanatory power of the research model, $\mathrm{R}^{2}$ value of satisfaction and continuance intention are $71.4 \%$ and $51.8 \%$ respectively. The analysis results indicate that the four value streams perceived by customers, specifically functional value, emotional value, economic value and environmental value, can explain a large variance of the endogenous variables. The results demonstrate a good explanatory power of the proposed theoretical model.

\subsubsection{Common Method Bias}

This study conducted a common method bias (CMB) analysis in SmartPLS to examine if CMB is a concern in our study. Following [46]'s approach, this study first added a method construct in the structural model, and then calculated each indicator's variances substantively explained by the principal construct as well as by the method construct. The analysis results indicate that the average variance explained by the principal constructs is 0.947 , while the average variance explained by the method construct is 0.002 . The ratio of substantive variance to method variance is about $473: 1$. The results demonstrate that common method bias is not a serious concern in this study, as suggested by [46].

\subsubsection{Post-hoc analysis}

Previous literature in IT adoption and usage argued that gender may play a significant role in explaining individuals' behavioral differences $[41,47]$. Compared with females, males are more "pragmatic" and usually have a greater emphasis on practical benefits and achievement needs [44]. While females are likely to pay more attention to the price of a product or service, and are more cost conscious than males [31]. In order to further examine if the relative influences of the four value streams on customer satisfaction are contingent upon gender, this study conducted a multi-group analysis between male and female users, as suggested in the previous literature [45]. Following the calculation approach suggested by [37, 42], this study statistically tested the significance of path coefficient differences across the two groups. The t-test analysis results are illustrated in Table 6 . 


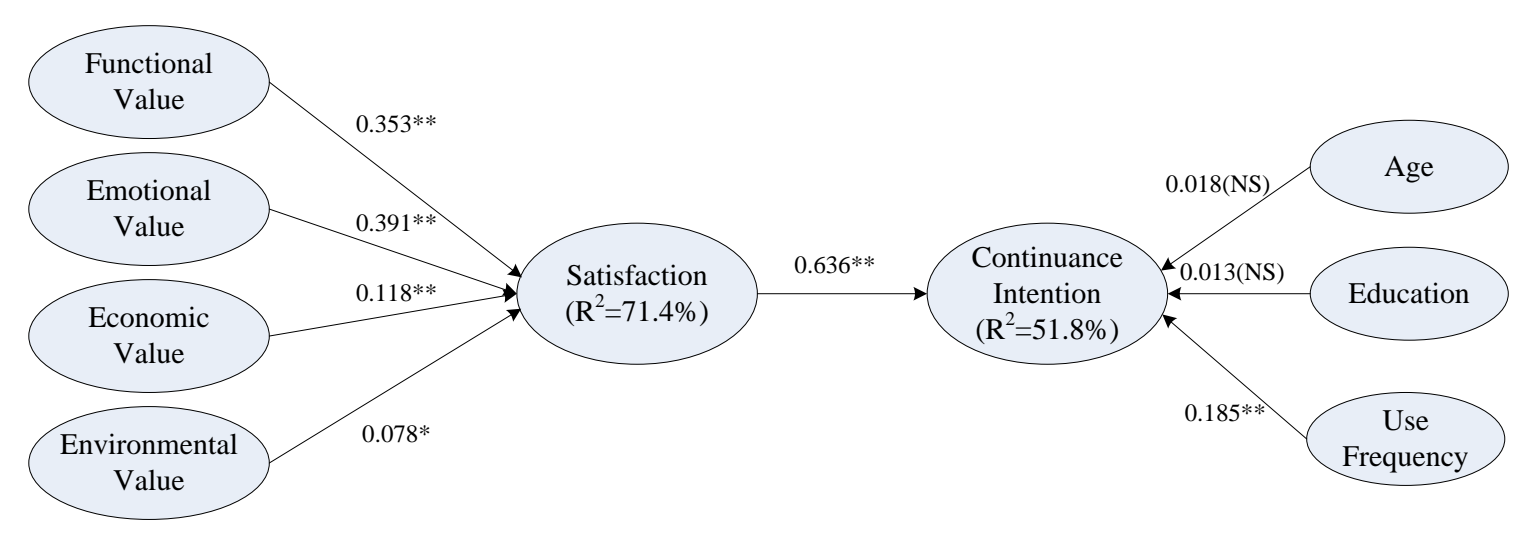

(Notes: ** represents $\mathrm{p}<.01$; represents $\mathrm{p}<.05$; NS represents not significant)

Figure 2. Structural model analysis results-overall samples

Table 6 Path Coefficient Comparison between Male and Female Users

\begin{tabular}{l|l|l|l}
\hline \multirow{2}{*}{ Path Relationship } & Path coefficients & \multirow{2}{*}{$\mathrm{t}_{\text {spooled }}$} \\
\cline { 2 - 4 } & Male Users $\left(\mathrm{N}_{1}=149\right)$ & Female Users $\left(\mathrm{N}_{2}=144\right)$ & $5.397 * *$ \\
\hline Functional Value $\rightarrow$ Satisfaction & $0.366^{* *}$ & $0.321^{* *}$ & $2.067 *$ \\
\hline Emotional Value $\rightarrow$ Satisfaction & $0.400^{* *}$ & $0.380^{* *}$ & $-20.454^{* *}$ \\
\hline Economic Value $\rightarrow$ Satisfaction & $0.054(\mathrm{NS})$ & $0.186^{* *}$ & $10.554^{* *}$ \\
\hline Environmental Value $\rightarrow$ Satisfaction & $0.128^{* *}$ & $0.023(\mathrm{NS})$ & \\
\hline
\end{tabular}

(Note:*P $<0.05, * * \mathrm{P}<0.01$, NS represents Not Significant)

As noted in Table 6, the path coefficient from functional value to satisfaction is significantly larger for male users than female users $\left(\beta_{\text {Males }}=0.366\right.$, $\left.\beta_{\text {Females }}=0.321, t_{\text {spooled }}=5.397\right)$. The result suggests that male users are more pragmatic and focus more on the productivity related benefits of bicycle sharing service. Moreover, the effect of emotional value on satisfaction is slightly stronger for male users than female users $\left(\beta_{\text {Males }}=0.400, \beta_{\text {Females }}=0.380, \mathrm{t}_{\text {spooled }}=2.067\right)$, indicating that hedonic benefits play a more significant role in influencing male users' affective reaction towards the bicycle sharing service. As illustrated in Table 6, the path coefficient from economic value to satisfaction is significantly larger for female users than male users $\left(\beta_{\text {Males }}=0.054, \quad \beta_{\text {Females }}=0.186, \quad t_{\text {spooled }}=-20.454\right) . \quad$ The result demonstrates that female users concern more on monetary cost, and are more likely influenced by cost reduction of bicycle sharing service. Moreover, the path coefficient from economic value to satisfaction is significantly larger for male users than female users $\left(\beta_{\text {Males }}=0.128, \quad \beta_{\text {Females }}=0.023, \quad t_{\text {spooled }}=-10.554\right) . \quad$ The result indicates that male users are more likely to generate a higher affective appraisal of the bicycle sharing service if they perceive a higher environmental benefit from the service.

\section{Theoretical and Practical Implications}

For theoretical implications, this study makes three major contributions to the extant literature. Firstly, this study adopts a value creation theoretical framework in the context of sharing economy, and uncovers the impact mechanism of four specific value streams, specifically functional value, emotional value, economic value and environmental value, on user satisfaction and continuance intention of bicycle sharing service. The four value streams can explain a large variance of user satisfaction, demonstrating a good explanatory power of the proposed research model. Secondly, this study extends [16]'s value creation theoretical framework by introducing "environmental value" as a significant value stream in the typical context of bicycle sharing. The empirical results indicate that environmental value perceived by customers plays a significant role in promoting customer satisfaction and continuance intention. The research findings can further enrich value creation theory in the new context of sharing economy. Thirdly, this study uncovers the moderating effect of gender on the relationship between the four value streams and customer satisfaction. The multi-group analysis demonstrates that male users prefer functional value, emotional value and environmental value, while female users focus more on economic value when using the bicycle sharing service. The empirical findings can further extend the boundary condition of the proposed research model. 
For practical implications, this study can serve as a theoretical framework for administrators to evaluate value streams of bicycle sharing service, and formulate appropriate strategies regarding the development, operations, and maintenance of third-party platforms. Firstly, the platform needs focus more on the technical benefits and joyful experiences of bicycle sharing service, and design more practical and vivid functions to enhance customer satisfaction. Secondly, the platform needs pay attention to the economic benefits of bicycle sharing service, and provide more coupons to customers according to their usage experiences, especially for female users who care more about monetary cost. Thirdly, considering the significance of environmental value of bicycle sharing service, the platform can send customers more information regarding green consumption and ecological sustainability. This strategy may be more effective for male users.

\section{Conclusions}

Drawing upon value creation theoretical framework, this study develops a research model to examine the impact mechanism of four value streams on customer satisfaction and continuance intention. An online survey was distributed to OFO and Mobike users in China, and 293 valid questionnaires were returned back. Structural equation modelling analysis results suggest that functional value, emotional value, economic value and environmental value have positive influences on customer satisfaction. Customer satisfaction, in turn, is positively associated with continuance intention of bicycle sharing service. A post-hoc analysis further suggests that there exists gender difference regarding the influences of the four value streams on customer satisfaction. There are several limitations in this study that leave open future research directions. Firstly, this study was conducted in China and data was collected from OFO and Mobike users, which may limit the generalization of the research findings. Future studies can collect data from other bicycle sharing platforms of different countries, in order to further explore the cultural issue of bicycle sharing usage. Secondly, future research can also conduct a longitudinal study and collect data at different time periods, in order to examine if the relative influences of the four value streams change over time.

\section{Acknowledgements}

This research was supported by the National Natural Science Foundation of China (71771064) and the Ministry of Education of Humanities and Social Science Project (17YJC630118).

\section{References}

[1] R. Botsman, and R. Rogers, What's mine is yours: the rise of collaborative consumption, Harper Collins Publishers, New York, 2011.

[2] M. Böckmann, "The sharing economy: It is time to start caring about sharing; value creating factors in the sharing economy", 1st IBA Bachelor Thesis Conference, The Netherlands, Enschede, June 27th, 2013.

[3] Hamari, Juho, M. Sjöklint, and A. Ukkonen. "The sharing economy: Why people participate in collaborative consumption", Journal of the Association for Information Science \& Technology, 2016, pp. 2047-2059.

[4] R. Belk, "You are what you can access: Sharing and collaborative consumption online", Journal of Business Research, 2014, pp. 1595-1600.

[5] PWC. The sharing economy, 2015.

[6] IResearch. Research report of bicycle-sharing industry in China, http://www.iresearch.com.cn/report/2961.html, 2017.

[7] A. K. Krontalis, "Why ridesharing? Investigating factors driving commuters' intention and ridesharing behavior in Jakarta", Master Thesis in Business and Social Sciences, Aarhus University, 2016.

[8] J. Lan, , Y. Ma, D .Zhu, D. Mangalagiu, and T.F. Thornton, "Enabling Value Co-Creation in the Sharing Economy: The Case of Mobike", Sustainability, 2017, pp. 1-20.

[9] Z. Shao, C. Y. Ge, "Impact of Service Quality on Individuals' Continuance Intention of the Bicycle-Sharing Application", The 22th Pacific Asia Conference on Information Systems (PACIS), Yokohama, Japan, June 26-30th, 2018.

[10] A. R.d. Águila-Obra, A. Padilla-Meléndez, and C. Serarols-Tarrés, "Value creation and new intermediaries on Internet. An exploratory analysis of the online news industry and the web content aggregators", International Journal of Information Management, 2017, pp. 187-199.

[11] C. Kim and D. J. Kim, "Uncovering the value stream of digital content business from users' viewpoint", International Journal of Information Management, 2017, pp. 553-565.

[12] T. R. Dillahunt and A. R. Malone, "The promise of the sharing economy among disadvantaged communities", in the proceedings of the 33rd annual ACM conference on human factors in computing systems, Seoul, Republic of Korea, 2015 .

[13] Lee, Z.W., Chan, T.K., Balaji, M.S. and Chong, A.Y.L. "Why people participate in the sharing economy: an empirical investigation of Uber", Internet Research, https://doi.org/10.1108/IntR-01-2017-0037, 2018.

[14] A. Zeithaml, Valarie, "Consumer Perceptions of Price, Quality and Value: A Means-end Model and Synthesis of Evidence", Journal of Marketing, 1988, pp. 2-22.

[15] B. Woodruff, Robert, "Customer Value: The Next Source for Competitive Advantage", Journal of the Academy of Marketing Science, 1997, pp. 139-153.

[16] J. C. Sweeney, and G. N. Soutar, "Consumer perceived value: The development of a multiple item scale", Journal of Retailing, 2001, pp. 203-220.

[17] K.. Yang, and L. D. Jolly, "Value-added mobile data services: The antecedent effects of consumer value on using 
mobile data services", International Journal of Mobile Marketing, 2006, pp. 11-17.

[18] B. J. Babin, W. R. Darden and M. Griffin, "Work and/or fun: measuring hedonic and utilitarian shopping value", Journal of Consumer Research, 1994, pp. 644-656.

[19] W. B. Dodds, K. B. Monroe and D. Grewal, "Effects of Price, Brand, and Store Information on Buyers", Journal of Marketing Research 1991, pp. 307-319.

[20] R. L. Oliver, "A cognitive model of the antecedents and consequences of satisfaction decisions," Journal of Marketing Research, 1980, pp. 460-469.

[21] P. G. Patterson, L. W. Johnson, and R.A. Spreng, "Modeling the Determinants of Customer Satisfaction for Business-to-Business Professional Services", Journal of the Academy of Marketing Science 1997, pp. 4-17.

[22] A. Bhattacherjee, "Understanding information systems continuance: An expectation-confirmation model", MIS Quarterly, 2001b, pp. 351-370.

[23] M. H. Hsu, C. M. Chiu, and T. L. Ju, "Determinants of continued use of the www: An integration of two theoretical models", Industrial Management \& Data Systems, 2004, pp. 766-775.

[24] C. L. Hsu, and C. C. Lin, "What drives purchase intention for paid mobile apps? - an expectation confirmation model with perceived value", Electronic Commerce Research \& Applications, 2015, pp. 46-57.

[25] X. Lin, M. Featherman, and S. Sarker, "Understanding factors affecting users social networking site continuance", Information \& Management, 2016, pp. 1-13.

[26] A. Bhattacherjee, "An empirical analysis of the antecedents of electronic commerce service continuance", Decision Support Systems, 2001a, pp. 201-214.

[27] Fishbein, Martin, and I. Ajzen, "Belief, Attitude, Intention and Behaviour: an introduction to theory and research." Philosophy \& Rhetoric, 1980, pp. 842-844.

[28] Wu, X., Zhou, H., Hu, M., and Li, J., "Perceived values, satisfaction and continuance: an empirical examination of users of 3G services", Journal of Psychological Science, 2012, pp. 943-950.

[29] J. C. Fandos Roig, J. S. García, and M. Á. Moliner Tena, "Perceived value and customer loyalty in financial services", The Service Industries Journal, 2009, pp. 775-789.

[30] L. Liu, and N. Zhang, "Research on the relationship between customer perceived value, satisfaction and loyalty-empirical analysis based on the electronic commerce market", Journal of Information Resources Management, 2016.

[31] V. Venkatesh and F. D. Davis, "Consumer acceptance and use of information technology: extending the unified theory of acceptance and use of technology", MIS quarterly, 2012, pp. 157-178.

[32] R. Cheung, A. Y. C. Lam, and M. L. Mei,. "Drivers of green product adoption: the role of green perceived value, green trust and perceived quality", Journal of Global Scholars of Marketing Science, 2015, pp.232-245.

[33] M .G. Luchs, R. W. Naylor, R. L. Rose, J. R. Catlin, R. Gau, and S. Kapitan, "Toward a sustainable marketplace: Expanding options and benefits for consumers", Journal of
Research for Consumers, 2011, pp. 1-12.

[34] M. Phipps, L. Ozanne, M. Luchs, S. Subrahmanyan, S. Kapitan, and J. Catlin, "Understanding the inherent complexity of sustainable consumption: A social cognitive framework", Journal of Business Research, 2013, pp. 12271234.

[35] W. T. Wang, Y. S. Wang, and E. R. Liu, "The stickiness intention of group-buying websites: The integration of the commitment-trust theory and e-commerce success model", Information \& Management, 2016, pp. 625-642.

[36] M. H. Huang, and Z. H. Cheng, "A longitudinal comparison of customer satisfaction and customer-company identification in a service context", Journal of Service Management, 2016, pp. 730-750.

[37] W. W. Chin, B. L. Marcolin, and P. R. Newsted, "A partial least squares latent variable modeling approach for measuring interaction effects: results from a monte carlo simulation study and an electronic-mail emotion/adoption study”, Information Systems Research, 2003, pp. 189-217.

[38] D. Gefen, D. W. Straub, and M. C. Boudreau, Structural equation modeling and regression: guidelines for research practice, Communications of the Association for Information Systems, 2000.

[39] Temme, Dirk, H. Kreis, and L. Hildebrandt. "PLS path modeling: a software review”, Sfb Discussion Papers, 2006, pp.1-27.

[40] A. M. Konrad, J. E. ritchie, P. Lieb, and E. Corrigall, "Sex differences and similarities in job attribute preferences: A meta-analysis", Psychological Bulletin, 2000, pp. 593-641.

[41] V. Venkatesh, and M.G. Morris, "Why don't men ever stop to ask for directions? Gender, social influence, and their role in technology acceptance and usage behavior", MIS Quarterly, 2000, pp. 115-139.

[42] M. Keil, B. C. Y. Tan, K. K. Wei, T. Saarinen, V. Tuunainen, and A. Wassenaar, "A cross-cultural study on escalation of commitment behavior in software projects", MIS Quarterly, 2000, pp. 299-325.

[43] M. Zhang, L. Guo, M. Hu, and W. Liu, "Influence of customer engagement with company social networks on stickiness: mediating effect of customer value creation", International Journal of Information Management, 2016, pp. 229-240.

[44] V. Venkatesh, and M.G. Morris, "Why don't men ever stop to ask for directions? Gender, social influence, and their role in technology acceptance and usage behavior", MIS Quarterly, 2000, pp.115-139.

[45] R. Chen, and S. K. Sharma, "Learning and self-disclosure behavior on social networking sites: the case of facebook users", European Journal of Information Systems, 2015, pp. 93-106.

[46] H. G. Liang, N. Saraf, Q. Hu, and Y. J. Xue, "Assimilation of Enterprise Systems: The Effect of Institutional Pressures and the Mediating Role of Top Management", MIS Quarterly, 2007, pp.59-87.

[47] Z. Shao, "Examining the impact mechanism of social psychological motivations on individuals' continuance intention of MOOCs: The moderating effect of gender", Internet Research, 2018, pp. 232-50. 